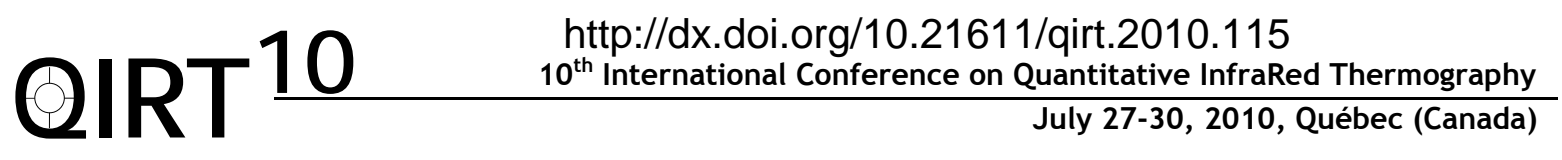

\section{MULTISPECTRAL OPTICOTHERMAL SYSTEM FOR THE PROCESS DYNAMICS MEASUREMENT IN THE MATERIAL STRENGTH EXAMINATIONS}

\author{
Dr.-Eng Leszek Rozanski, Dr.-Eng. MSc.-Eng. Andrzej Trafarski ${ }^{1}$ \\ Miroslaw Grzelka ${ }^{1}$, Marek Radkei ${ }^{2}$
}

\begin{abstract}
${ }^{1}$ Poznan University of Technology, Institute of Mechanical Technology, Faculty of Mechanical Engineering and Management, Division of the Metrology and Measurement Systems, PL60-965 Poznań, ul. Piotrowo 3, tel.: +4861665 2360 ; fax: +48 616652363 , leszek.rozanski@put.poznan.pl, a.trafarski@gmail.com miroslaw.grzelka@put.poznan.pl
\end{abstract}

${ }^{2}$ ITA Polska Sp. J. - Zaawansowane Systemy Narzędziowe i Pomiarowe, ul. Świerzawska 1/57, 60-321 Poznań, Telefon/Fax: (061) 861 11 71, e-mail: mr@ita-polska.com.pl

Keywords: Coordinate Measuring Machine, optic dynamic scaning, multispectral optothermal measurement, thermographic

\section{TYPICAL COORDINATE MEASURING TECHNIQUE}

Coordinate measuring technique is the most modern and innovative technique applied for the measurement of geometrical features that determine the accuracy of manufactured detail. Typically, measuring software identify the probing points and calculate the fitting elements for measured detail. The measuring information is gained from the various types of measuring heads like contact switching heads or contact scanning heads (with continual contact of probe ball tip with measured surface). The last one could be performed with active or passive type of probing head and enable to collect large number of probing points in short time. That means high accuracy of the detail reproduction.

Coordinate measuring machines are equipped with advanced measuring software for the measurement of complicated details like various type of gears (cylindrical or bevel gears, or helicoidal involute ones), crankshafts or turbine blades. Recently also the optical metrology was applied in the coordinate measurements through the non-contact scanning heads or CCD cameras. Scanning heads found wide application in the motor industry, and combined with measuring arms they form quick and accurate measurement systems for inspection of car bodies or freeform surfaces. This way coordinate measurement became the most important and most advanced system for industrial measurement and reverse engineering processes.

\section{OPTICAL COORDINATE MEASUREMENT TECHNIQUE}

The newest systems are often called the optical scanners for identification of deformation. They found wide application areas in many branches of industry, especially in the reverse engineering when a new shape is projected and modified. Fig. 1 presents examples of the available devices.

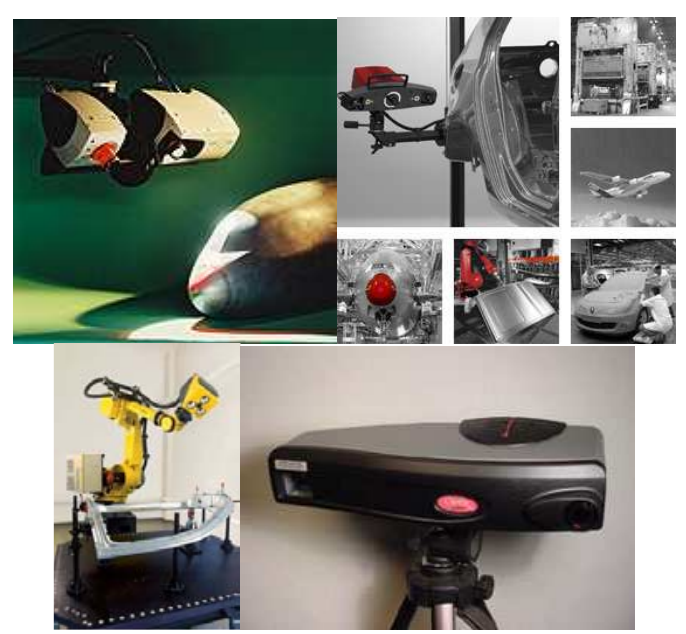

Fig. 1. Examples of the 3D optical scanners.

Until recent, the coordinate measuring technique was applied for static measurement of details (unchanged position of the detail in measuring space). It was also an effective method of deformation identification after the process shaping the measured detail. Measurement before and after such a process enabled to identify deviations or deformations in the defined measuring points and to perform further analysis of the process. The phenomena taking place 
during the process (dynamical ones) in very short time, often unregistered by the human eye, were neither measured nor analyzed metrologically.

Recently, the development of the optical scanners enabled the geometrical analysis of the processes occurring in very short time. They enable to measure and to determine local deformations and movement of the measuring points in the coordinate system with frequency up to 500 per second (Fig. 2).

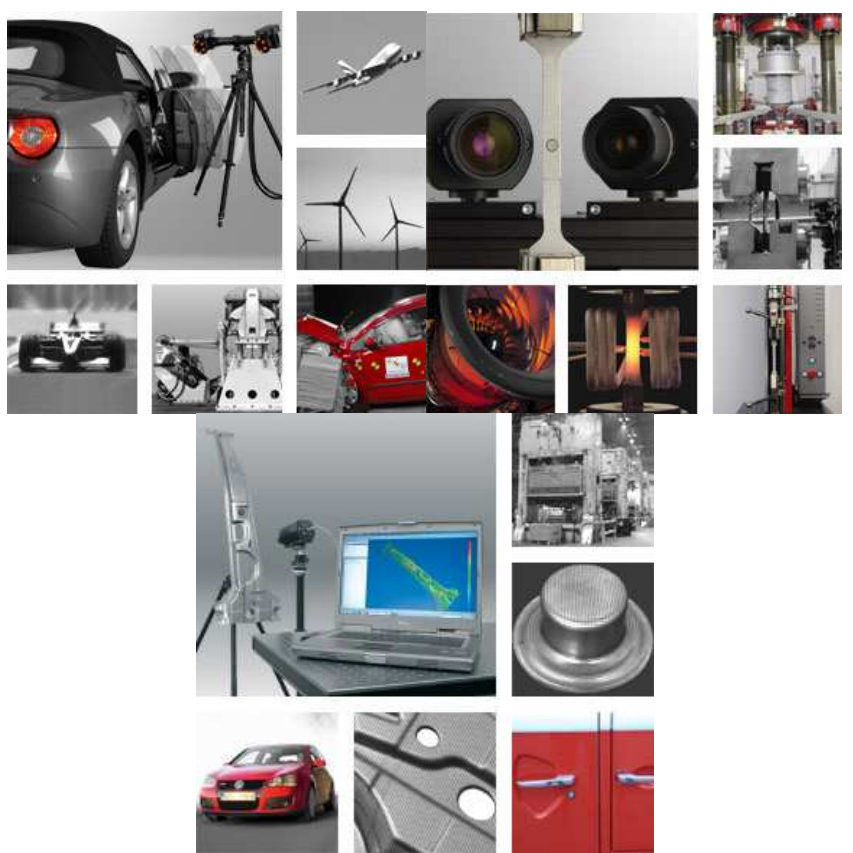

Fig. 2. Examples of the optical scanners for 3D dynamic measurement

The example of such measurement is the measurement of the stretched sample. Fig. 3 presents the sequence of the measurement with the chosen measuring points. In this method, the dynamical 3D scanner cooperates with tensile testing machine and they are the measurement system. Its advantage is that the measurement could be repeated many times for differently defined measuring points and coordinate systems.

Additionally, when the thermovisual camera with appropriate control system and measurement programs is added, the analysis could become more complex through the measurement of temperature in any point and any time. In the Division of Metrology and Measurement System (Poznan University of Technology) the effort to create such a system was undertaken. The tensile testing machine, optical scanner and thermovisual camera were integrated into the multispectral optothermal measurement system.

\section{INTEGRATED MULTISPECTRAL OPTOTHERMAL MEASUREMENT SYSTEM}

Nowadays, the solution of scientific and technical problems is closely connected with creation of images that cover with their spectral sensitivity possibly wide range of the electromagnetic waves. One of the important places among this type of devices belongs to the cameras able to work both in visible and infrared spectrum. This kind of systems contains in fact two different type cameras connected physically and with software. They perform so called FUSION function that enable to superpose and interfere thermal and visual images. In the thermal diagnostics, this technique enables easy determination of the location of the points with thermal anomaly.

The proposed system, however, has a different approach. The thermographic camera was connected with 3D optical scanner. The system provided incomparably better ability to collect metrological information on the dynamical processes of the deformation of object, connected with thermal information. The integrated multispectral optothermal measurement system could be successfully applied for the dynamical examinations of processes connected with strength tests of the materials (stretching, tear, compression, shearing, bending etc.). Especially useful it is for the tests of metals and monitoring of processes of destruction of various composite materials. It enables geometrical and thermal registration of the process with determination of the localization of crack appearance, direction of its propagation and break.

The devices included into the described system are optical scanner and thermovisual system equipped with interface with option of the image sequence record. The work of both devices is synchronized by the adjustable generator of the initiating pulses. The system underwent examinations on the metrological conditions of the radiational methods $f$ temperature measurement. The effective emissivity coefficient of the layer covering the sample was determined experimentally. The temperature measurement method was differential one with reference to the standard radiation source (technical model of black body). 


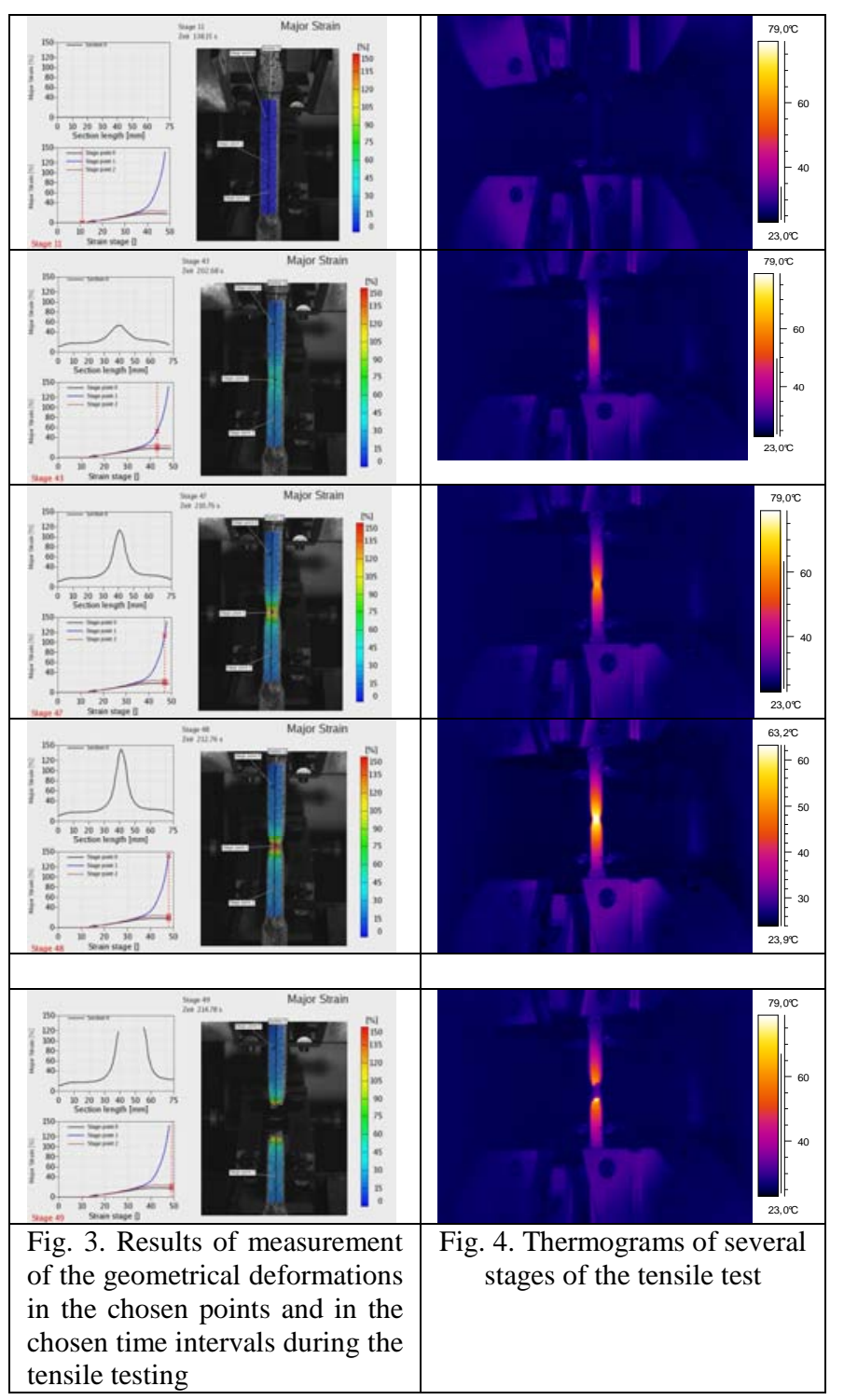

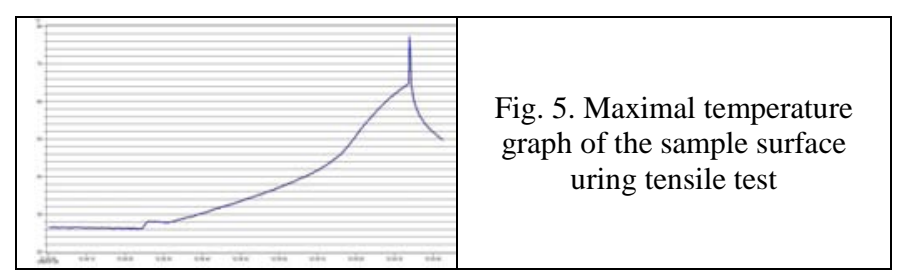

\section{REFERENCES}

[1] R. D. Hudson, Infrared System Engineering, Wiley Interscience, New York, 1969.

[2] X. P. V. Maldague, Theory and Practice of Infrared Technology for Nondestructive Testing. John Wiley \& Sons, Inc., New York, 2001

[3] W. Minkina, Pomiary termowizyjne - przyrzqdy i metody, Wydawnictwo Politechniki Częstochowskiej, Częstochowa , 2004

[4] T. Luhmann, S. Robson, S. Kyle, I. Harley: Close Range Photogrammetry: Principles, Techniques and Applications (Hardcover), Published by Whittles Publishing, Dumbeath Mains Cottages, Dumbeath, Caithness KW6 6EY, Scotland, UK 2006, ISBN 0470-10633-6 